\title{
Article \\ Dual Role of Acid Rain and Pyricularia oryzae on Growth, Photosynthesis and Chloroplast Ultrastructure in Rice Seedlings
}

\author{
Hongru Li ${ }^{1}$, Qiuyuan $\mathrm{Xu}^{2}{ }^{2}$, Chao Li ${ }^{1}$, Jiaen Zhang ${ }^{1,3,4,5,6, * \mathbb{D}}$, Qi Wang ${ }^{1}$, Huimin Xiang ${ }^{1,3,4,5,6}$, Yiliang Liu ${ }^{1}$, \\ Hui Wei ${ }^{1,3,4,5,6}$ and Zhong Qin $1,3,4,5,6$
}

1 Guangdong Provincial Key Laboratory of Eco-Circular Agriculture, South China Agricultural University, Guangzhou 510642, China; lihongru19@stu.scau.edu.cn (H.L.); lichaolc@stu.scau.edu.cn (C.L.); qwang@stu.scau.edu.cn (Q.W.); hmxiang@scau.edu.cn (H.X.); ly1981221@stu.scau.edu.cn (Y.L.); weihui@scau.edu.cn (H.W.); q_breeze@126.com (Z.Q.)

2 College of Architecture and Urban Planning, Fujian University of Technology, Fuzhou 350118, China; xuqy@fjut.edu.cn

3 Department of Ecology, College of Natural Resources and Environment, South China Agricultural University, Guangzhou 510642, China

4 Guangdong Engineering Research Center for Modern Eco-Agriculture and Circular Agriculture, Guangzhou 510642, China

5 Key Laboratory of Agro-Environment in the Tropics, Ministry of Agriculture and Rural Affairs, South China Agricultural University, Guangzhou 510642, China

6 Guangdong Laboratory for Lingnan Modern Agriculture, Guangzhou 510642, China

* Correspondence: jeanzh@scau.edu.cn; Tel.: +86-20-8528-5505

check for updates

Citation: Li, H.; Xu, Q.; Li, C.; Zhang, J.; Wang, Q.; Xiang, H.; Liu, Y.; Wei, H.; Qin, Z. Dual Role of Acid Rain and Pyricularia oryzae on Growth, Photosynthesis and Chloroplast Ultrastructure in Rice Seedlings. Agronomy 2022, 12, 567. https:// doi.org/10.3390/agronomy12030567

Received: 11 December 2021

Accepted: 4 February 2022

Published: 24 February 2022

Publisher's Note: MDPI stays neutral with regard to jurisdictional claims in published maps and institutional affiliations.

Copyright: (C) 2022 by the authors. Licensee MDPI, Basel, Switzerland. This article is an open access article distributed under the terms and conditions of the Creative Commons Attribution (CC BY) license (https:// creativecommons.org/licenses/by/ $4.0 /)$.

\begin{abstract}
Rice is widely planted and serves as staple food in the world, but it is often exposed to acid rain and rice blast (Pyricularia oryzae). In this work, we analyzed the effects of co-exposure to simulated acid rain (SAR) and P. oryzae on the photosynthetic growth of rice seedlings. We found that the growth, photosynthesis, and chloroplast ultrastructure of rice seedlings were damaged under single treatments of $P$. oryzae and strong acid rain $(\mathrm{pH}$ 2.0) but increased under medium acidity acid rain ( $\mathrm{pH} 4.0$ ). Similarly, when plants were exposed to both P. oryzae and acid rain, $\mathrm{pH} 4.0$ mitigated the changes of growth, photosynthetic characteristics, and chloroplast ultrastructure induced by P. oryzae, but $\mathrm{pH} 2.0$ aggravated these changes. In addition, we found that significant differences in chlorophyll content (chlorophyll a and chlorophyll b) correlated with transpiration rate (Tr) under the combined stress of acid rain and P. oryzae at $\mathrm{pH} 4.0$ and $\mathrm{pH}$ 2.0. Medium-acidity acid rain alleviated the harm caused by P. oryzae on rice growth by enhancing synergistic regulatory mechanisms of photosynthetic traits to increase plant resistance tolerance. The effect of $P$. oryzae on photosynthetic traits of rice was regulated by acidity of acid rain.
\end{abstract}

Keywords: acid rain; Pyricularia oryzae; photosynthesis; chlorophyll fluorescence; chloroplast ultrastructure

\section{Introduction}

Rice (Oryza sativa) is a critical economic crop worldwide. Rice blast caused by the filamentous fungus Pyricularia oryzae significantly and negatively impacts global rice yields each year [1,2]. Rice blast induces diamond-shaped brown necrosis spots with a grayish white center on the surface of the infected leaves, thereby reducing the green leaf area [3,4]. The lesions caused by P. oryzae can damage the cuticle and stomata, decreasing the stomatal conductance, changing the transpiration, or reducing the efficiency of the photosynthetic process [5-7]. For example, rice leaves infected with P. oryzae will cause leaf tissue senescence and death, cell deformations or collapse, destruction of chloroplast ultrastructure, interference with photosynthesis and the protective system, and ultimately inhibits rice growth [8]. 
Acid rain is another severe global environmental problem [9]. The southern region of China is the third biggest acid rain region following Europe and North America [10]. Studies indicate that simulated acid rain (SAR) affects plant growth by changing the composition and structure of chloroplast, decreasing chlorophyll content, and disrupting the balance between light reactions and dark reactions of various physiological processes [11-13]. Variations in the acidity of acid rain can also induce a diametrically opposite effect on light and dark reactions. Previous studies concluded that when the $\mathrm{pH}$ value exceeds the maximum tolerance range of plants, acid rain can induce foliar necrosis, cause structural changes in the photosynthetic apparatus, including flocculation of the thylakoids lamellar structure and thinning of thylakoid grana-thus inhibiting photosynthesis [14-17]. Liu et al. (2019) [18] found that SAR of $\mathrm{pH} 4.5$ improved the absorption of light energy, enhanced electron transport, improved conversion of light energy, and increased net photosynthesic rate (Pn). On the contrary, SAR of pH 2.5 damages the PSII reaction center of the photoreaction, and restricts electron transfer, resulting in reduced chlorophyll fluorescence parameters, thereby inhibiting the absorption of light energy [19]. Various plants show different tolerances to acid rain [20]. For example, Jatropha curcas [21] and rice (Oryza sativa) [22] can tolerate SAR at $\mathrm{pH} 4.5$, actually improving in biomass, plant height, and basal diameter, while soybean (Glycine max) shows the opposite trend in these traits [23].

In fact, plants are typically subjected to multiple harmful stressors in nature; disease and acid rain coexist simultaneously in many agricultural systems. Different stresses interactions may show additive, antagonistic, or synergistic effects. Previous studies found that SAR and P. oryzae interactively change the activities of important antioxidant enzymes and the content of metabolites related to disease resistance in rice, and antagonistically/synergistically affected disease index $[4,24]$. However, there is no systematic information on the effects of SAR on the photosynthetic processes of rice seedlings under $P$. oryzae infections. Therefore, the purpose of this study was to investigate (1) the response of growth indexes, chloroplast ultrastructure, photosynthetic pigments, and photosynthetic parameters to combined stress of acid rain and P. oryzae, and (2) the link between plant growth characteristics and photosynthetic physiology of rice seedlings under the compound stress of acid rain and P. oryzae. The results of this study will help deepen understanding of the mechanism of injuring rice photosynthetic system under the co-existence of SAR and P. oryzae.

\section{Materials and Methods}

\subsection{Experimental Materials and P. oryzae Culture}

The sampling depth of paddy soil was 0-30 cm. After collection, we air-dried and sieved the soil through a $3 \mathrm{~mm}$ sieve, and placed $20 \mathrm{~kg}$ into each plastic pot (51 cm long $\times 38.5 \mathrm{~cm}$ wide $\times 29 \mathrm{~cm}$ high). Rice seeds, Mei Xiang Zhan (PI 2006009) belongs to Indica, selected by the Rice Research Institute of Guangdong Academy of Agricultural Sciences, were sterilized in $0.1 \% \mathrm{HgCl}_{2}$ solution for $10 \mathrm{~min}$, and washed with deionized water. Seeds were then germinated in petri dishes with moistened filter papers for 6 days at $28-30^{\circ} \mathrm{C}$ in a light incubator. After that, the germinated seeds were planted to blue plastic pots to pre-cultivate. Nine seedlings were sown in each pot. After 15 days of growth, when the rice revealed three leaves and one heart, we started the experiment.

The desiccated filter paper pieces of wild-type strain Guy11 fungal hyphae and spores were incubated for 7-10 days at temperature of $24{ }^{\circ} \mathrm{C}$ to generate conidia, and a concentration of the spore suspension was adjusted to $1 \times 10^{5}$ conidia $/ \mathrm{mL}$ with a hemocytometer to prepare the spore suspension for later use. The conidia were sprayed on the rice leaves by a high-pressure spray gun [24].

\subsection{Preparation of $S A R$ Treatments}

We used a two-factor experiment design with acid rain and $P$. oryzae treatments. The $P$. oryzae infection included two treatments, inoculated and not inoculated with P. oryzae, and 
the SAR treatments included three levels: $\mathrm{pH} 7.0, \mathrm{pH} 4.0$, and $\mathrm{pH}$ 2.0. The amount of SAR sprayed was measured based on the annual precipitation $(1930.9 \mathrm{~mm})$ and average acid rain frequency $(29.7 \%)$ in the Guangdong Province in the past five years (2013-2017). The surface of each plastic pot $\left(808.5 \mathrm{~cm}^{2}\right)$ meant a total of $114.21 \mathrm{~L}$ of the SAR and controlled tap water were sprayed on the corresponding treatments respectively, during the cultivation period, 10 times a month from August 2018 to October 2018, with 3.8L sprayed from the top to each plastic pots each time [25]. In the present study, we applied 4:1 as the ratio of $\mathrm{SO}_{4}{ }^{2-}$ to $\mathrm{NO}_{3}{ }^{-}$in all the SAR treatments. There were six treatments: (1) the control treatment $(\mathrm{CK})$, in which rice seedlings without $P$. oryzae were sprayed with tap water (pH 7.0); (2) single treatment with P. oryzae in which seedlings were infected with P. oryzae and sprayed with tap water ( $\mathrm{pH} 7.0)$; (3) two single treatments with SAR in which seedlings without $P$. oryzae were sprayed with SAR solutions ( $\mathrm{pH} 4.0$ and 2.0); and (4) two combined treatments with SAR and P. oryzae in which rice seedlings were infected with P. oryzae and sprayed with SAR ( $\mathrm{pH} 4.0$ and 2.0). Nine replicates were established for each treatment.

\subsection{Determination of Rice Growth Indexes}

The growth indices include the dry weight, plant height, and leaf area (LA) for each rice seedling. Rice seedling height was the distance from the base of the plant to the leaf tip measured using a tape ruler. The LA was tested using a leaf area scanner (YMJ-P, Shandong, China). The rice seedlings were separated according to the roots, stems, and leaves, and put in an oven at $105^{\circ} \mathrm{C}$ for $2 \mathrm{~h}$, and then transferred to $80^{\circ} \mathrm{C}$ to dry to a constant weight [14].

\subsection{Chlorophyll Determination}

Chlorophyll and carotenoid contents were measured colorimetrically by the method described by Lichtenthaler et al. (1987) using absorbance in ultraviolet spectrophotometer recording that the wavelengths of chlorophyll a (Chla), chlorophyll b (Chlb), and carotenoids (Car) were at 470, 646, and $663 \mathrm{~nm}$ [26].

\subsection{Evaluation of Chlorophyll Photosynthetic Parameters and Fluorescence}

After the 90-day experiment, photosynthetic parameters of rice leaves were determined on the attached leaves (the penultimate leaf for each replication of each treatment), including photosynthetic rate $(\mathrm{Pn})$, stomatal conductance $(\mathrm{Gs})$, internal $\mathrm{CO}_{2}$ concentration $(\mathrm{Ci})$, and transpiration rate (Tr). All this was carried out using a portable photosynthesis system, Li-6400 (Li-Cor Inc., Lincoln, NE, USA) from 09:00 to 12:00 am [18].

Chlorophyll fluorescence parameters of the same leaves with photosynthetic parameters were determined using a portable chlorophyll fluorometer from 21:00 to 24:00 pm (Mini-PAMII, Wetzlar, Germany). The maximum quantum efficiency of PSII photochemistry (Fv/Fm), actual activity of (PSII), photochemical quenching (qP), and non-photochemical quenching of fluorescence (NPQ) were determined [27].

\subsection{Transmission Electron Microscopy (TEM)}

The parts in the top second leaf with typical disease symptoms were cut into $1 \mathrm{~mm} \times 3 \mathrm{~mm}$ pieces and placed in a $2 \%$ glutaraldehyde fixation solution. They were vacuumed until the leaf parts were immersed into the fixation solution and remained under $4{ }^{\circ} \mathrm{C}$ for 2 days. Then, leaves were washed with a phosphate buffer solution $(0.1 \mathrm{~mol} / \mathrm{L})$, fixed in $1 \%$ osmic acid for $3 \mathrm{~h}$, and washed with phosphate buffer solution $(0.1 \mathrm{~mol} / \mathrm{L})$ and dehydrated with ethanol. After dehydration, epoxypropane and Epon 812 embedding medium were used for replacement and penetration. The ultrathin microtome (LeicaUCT, Wetzlar, Germany) was used for slicing. Sections were stained with uranyl acetate and lead citrate, observed and photographed with TEM (Talos L120C, Thermo Fisher, Waltham, MA, USA) [28]. 


\subsection{Statistical Analysis}

A one-way analysis of variance (ANOVA) was performed using SPSS 22.0 (IBM Corp., Armonk, NY, USA). A two-way ANOVA analysis of variance was used to study the interactive effects of acid rain and P. oryzae on the growth indices and photosynthetic parameters of rice seedlings. The relationships between Chla or Chlb and Tr under the combined treatment of SAR and P. oryzae were verified by linear regression. Redundancy discriminant analysis (RDA) was performed to reveal the interactions between the acid rain $\mathrm{pH}, P$. oryzae, growth indices, photosynthetic pigment content, and photosynthetic characteristics by using Canoco 5.0 (Microcomputer Power, Ithaca, NY, USA). The structural equation model (SEM) was used to examine whether SAR pH and P. oryzae directly or indirectly affect growth indices by altering foliar photosynthetic pigments content and photosynthetic characteristics parameters with AMOS 24.0 (SPSS Inc., Chicago, IL, USA). All graphs were produced using Origin 9.1 (Origin Lab, Northampton, MA, USA).

\section{Results}

\subsection{Combined Effects of SAR and P. oryzae on Growth Indices of Rice Seedlings}

The plant height, leaf area, and biomass treated with $\mathrm{pH} 2.0$ showed a significant decrease compared with control, but they did not show changes in those treated with $\mathrm{pH} 4.0$ (Table 1). The plant height, leaf area, and biomass treated with P. oryzae, decreased by $22.02 \%, 51.45 \%$, and $32.39 \%$, respectively, compared with control $(p<0.05)$. The combination treatment of $\mathrm{pH} 4.0$ and P. oryzae significantly increased the plant height, leaf area, and the biomass compared with P. oryzae alone. However, the combination treatment of $\mathrm{pH} 4.0$ and $P$. oryzae significantly decreased plant height, leaf area, and biomass compared with the single treatment of $\mathrm{pH} 4.0$. The combination of $\mathrm{pH} 2.0$ and P. oryzae treatment decreased the plant height, leaf area, and the biomass compared with the single inoculation of P. oryzae and acid rain at pH 2.0 alone. Additionally, the plant height, leaf area, and the biomass of rice treated with $\mathrm{pH} 4.0$ and P. oryzae was higher than those treated with the combination treatment of $\mathrm{pH} 2.0$ and P. oryzae, increased by $24.41 \%, 135.95 \%$, and $50.74 \%$, respectively. The results of ANOVA indicated that there were significant interaction effects between acid rain and P. oryzae on the plant height, the leaf area, and biomass.

Table 1. Effect of SAR and P. oryzae on the growth indices of rice seedlings.

\begin{tabular}{cccc}
\hline $\begin{array}{c}\text { Acid Rain }(\mathbf{p H}) / \\
\text { Pyricularia oryzae }\end{array}$ & Height $(\mathbf{c m})$ & Leaf Area $\left(\mathbf{c m}^{2}\right)$ & Biomass $(\mathrm{g} / \mathbf{p l a n t})$ \\
\hline pH 7.0 (control) & $63.98 \pm 0.41 \mathrm{a}$ & $18.56 \pm 0.12 \mathrm{~b}$ & $2.13 \pm 0.03 \mathrm{~b}$ \\
pH 4.0 & $64.31 \pm 0.38 \mathrm{a}$ & $19.50 \pm 0.15 \mathrm{a}$ & $2.27 \pm 0.01 \mathrm{a}$ \\
pH 2.0 & $53.94 \pm 0.53 \mathrm{c}$ & $11.71 \pm 0.11 \mathrm{~d}$ & $1.53 \pm 0.01 \mathrm{~d}$ \\
P. oryzae & $49.89 \pm 0.47 \mathrm{~d}$ & $9.01 \pm 0.12 \mathrm{e}$ & $1.44 \pm 0.02 \mathrm{e}$ \\
pH 4.0 + P. oryzae & $58.96 \pm 0.85 \mathrm{~b}$ & $17.72 \pm 0.17 \mathrm{c}$ & $2.05 \pm 0.02 \mathrm{c}$ \\
pH 2.0 + P. oryzae & $47.39 \pm 0.63 \mathrm{e}$ & $47.39 \pm 0.63 \mathrm{e}$ & $1.36 \pm 0.02 \mathrm{f}$ \\
pH & $* * * * * * * *$ & $* * *$ \\
P. oryzae & $* * *$ & $* * *$ & $* * *$ \\
pH $\times$ P. oryzae & $*$ & $* *$ & $*$ \\
\hline
\end{tabular}

Note: In the same column, significant difference at $p<0.05$ was shown with different lowercase. Asterisks indicate the results of two-way ANOVA: ${ }^{* * *}, p<0.001$. Values are the average \pm standard error $(n=9)$.

\subsection{Combined Effects of SAR and P. oryzae on Photosynthetic Parameters of Rice Seedlings}

The Pn, Ci, Tr, and Gs in rice seedlings treated with $\mathrm{pH} 2.0$ showed a significant decrease compared with the control, but there was an increase when treated with $\mathrm{pH} 4.0$ treatment (Figure 1). Inoculated with P. oryzae treatment significantly decreased the $\mathrm{Pn}, \mathrm{Ci}$, $\mathrm{Tr}$, and Gs of rice seedlings compared with the control. The combination treatment of $\mathrm{pH} 4.0$ and $P$. oryzae significantly decreased the $\mathrm{Pn}, \mathrm{Ci}, \mathrm{Tr}$, and $\mathrm{Gs}$ in rice seedlings compared with the single treatment of $\mathrm{pH} 4.0$, reduced by $22.15 \%, 13.37 \%, 10.08 \%$, and $15 \%$, respectively. The Pn, Ci, Tr, and Gs of rice treated with a combination treatment of $\mathrm{pH} 2.0$ and P. oryzae were lower than that of the control and the single treatment with $\mathrm{pH} 2.0$, respectively. The 
results showed that the change in Pn in rice seedlings treated with acid rain and P. oryzae was similar to that of the growth indices (Table 1 and Figure 1). The results of ANOVA indicated that there were significant interaction effects between acid rain and P. oryzae on the photosynthetic parameters.
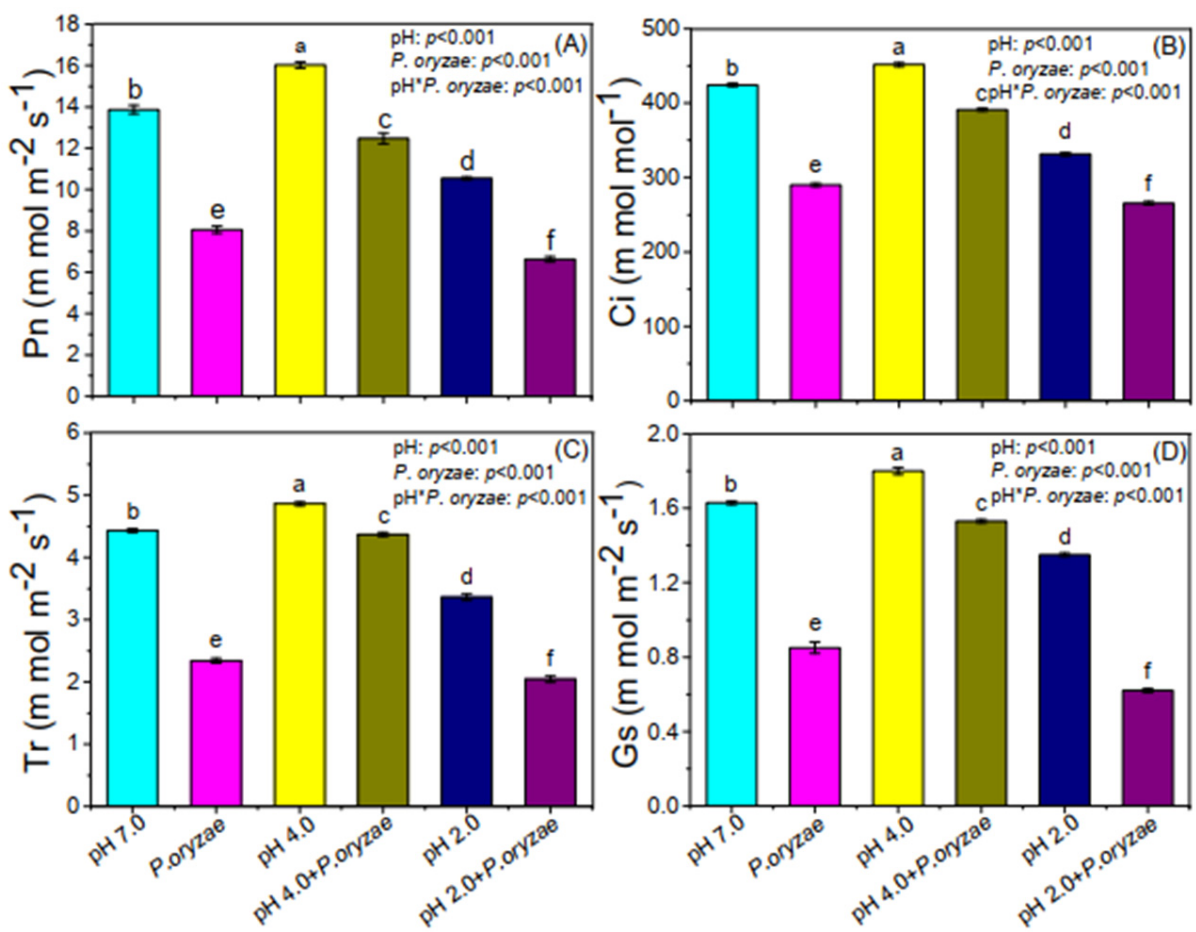

Figure 1. Effects of SAR and P. oryzae on the photosynthetic parameters of $\operatorname{Pn}(\mathbf{A}), \mathrm{Ci}(\mathbf{B}), \operatorname{Tr}(\mathbf{C})$, and Gs (D) in rice seedlings. Different lowercase letters indicate the significant difference between groups $(p<0.05)$. Values are the average \pm standard error $(n=9)$.

\subsection{Combined Effects of SAR and P. oryzae on Photosynthetic Pigment Content of Rice Seedlings}

Figure 2 shows that the Car content of rice seedlings treated with the single treatment of $\mathrm{pH} 4.0$ significantly increased compared with the control (Figure 2C), but the chlorophyll a (Chla), chlorophyll b (Chlb) content and the ratio of Chla to Chlb (Chla/Chlb) were not significantly different (Figure 2A,B,D). The single treatment with $\mathrm{pH} 2.0$ noticeably decreased the contents of Chla, Chlb, Car, and Chla/Chlb of rice seedlings compared with the control. Inoculated with P. oryzae treatment, the Chla, Chlb, Car, and Chla/Chlb contents of rice seedlings significantly decreased by $57.72 \%, 28.13 \%, 41.67 \%$, and $40.56 \%$, respectively, compared with the control. The Chla, Chlb, Car, and Chla/Chlb contents of rice seedlings treated with the combination treatment $\mathrm{pH} 4.0$ and $\mathrm{P}$. oryzae were higher than those of P. oryzae treatment alone. The contents of Chla, Chlb, Car, and Chla/Chlb treated with the combination treatment of $\mathrm{pH} 2.0$ and P. oryzae were lower than those of the control and $\mathrm{pH} 2.0$ treatment alone, respectively. The contents of Chla and Chlb treated with the combination treatment of $\mathrm{pH} 2.0$ and P. oryzae decreased $19.23 \%$ and $21.74 \%$, respectively, compared with P. oryzae alone. The results of ANOVA indicated that there were also significant interaction effects between acid rain and P. oryzae on the photosynthetic pigment content. 

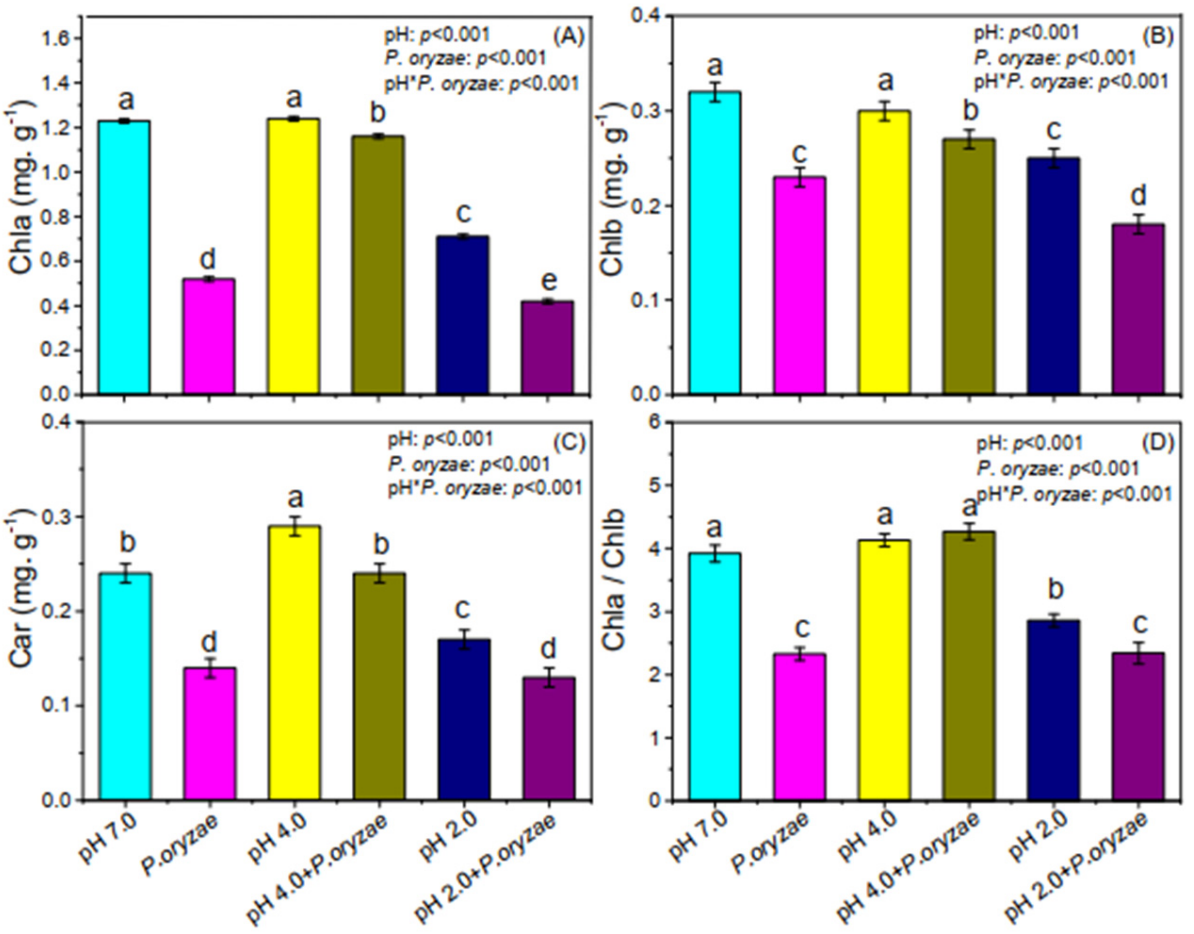

Figure 2. Photosynthetic pigment contents in rice seedlings under SAR and P. oryza treatment. Chlorophyll a (Chla, A), Chlorophyll b (Chlb, B), Cartenoid (Car, C), and ratio of Chlorophyll a to Chlorophyll b (Chla/Chlb, D) in rice seedlings. Different lowercase letters indicate significant different between groups $(p<0.05)$. Values are the average \pm standard error $(n=9)$.

\subsection{Combined Effects of SAR and P. oryzae on Chlorophyll Fluorescence of Rice Seedlings}

When rice seedlings were treated with single $\mathrm{pH}$ 4.0, the PSII and NPQ increased, but $\mathrm{Fv} / \mathrm{Fm}$ and qP did not differ significantly from the control, as shown in Figure 3. However, at $\mathrm{pH} 2.0$ treatment, the values of Fv/Fm, PSII, and NPQ decreased by $20.48 \%, 21.79 \%$, and $9.66 \%$, respectively, and the values of $\mathrm{qP}$ increased by $63.64 \%$, compared with the control. The treatment inoculated with P. oryzae significantly decreased the Fv/Fm, PSII, qP, and NPQ of rice seedlings, compared with the control. When rice seedlings were treated with the combination of $\mathrm{pH} 4.0$ and P. oryza, Fv/Fm, PSII, and NPQ were lower than those when treated with single $\mathrm{pH} 4.0$, whereas the value of $\mathrm{qP}$ was higher than that treated with single $\mathrm{pH}$ 4.0. Compared to P. oryzae alone, the combination treatment of $\mathrm{pH} 4.0$ and P. oryzae increased the Fv/Fm, PSII, and NPQ values, but reduced the $\mathrm{qP}$ value. Values of Fv/Fm, PSII, and NPQ treated with the combination of $\mathrm{pH} 2.0$ and P. oryza were lower than those of the single inoculation of $P$. oryza and $\mathrm{pH} 2.0$ treatment alone. Additionally, the value of $\mathrm{qP}$ was higher than that treated with single $\mathrm{pH}$ 2.0. The results of ANOVA indicated that there were significant interaction effects between acid rain and P. oryzae on the chlorophyll fluorescence. 

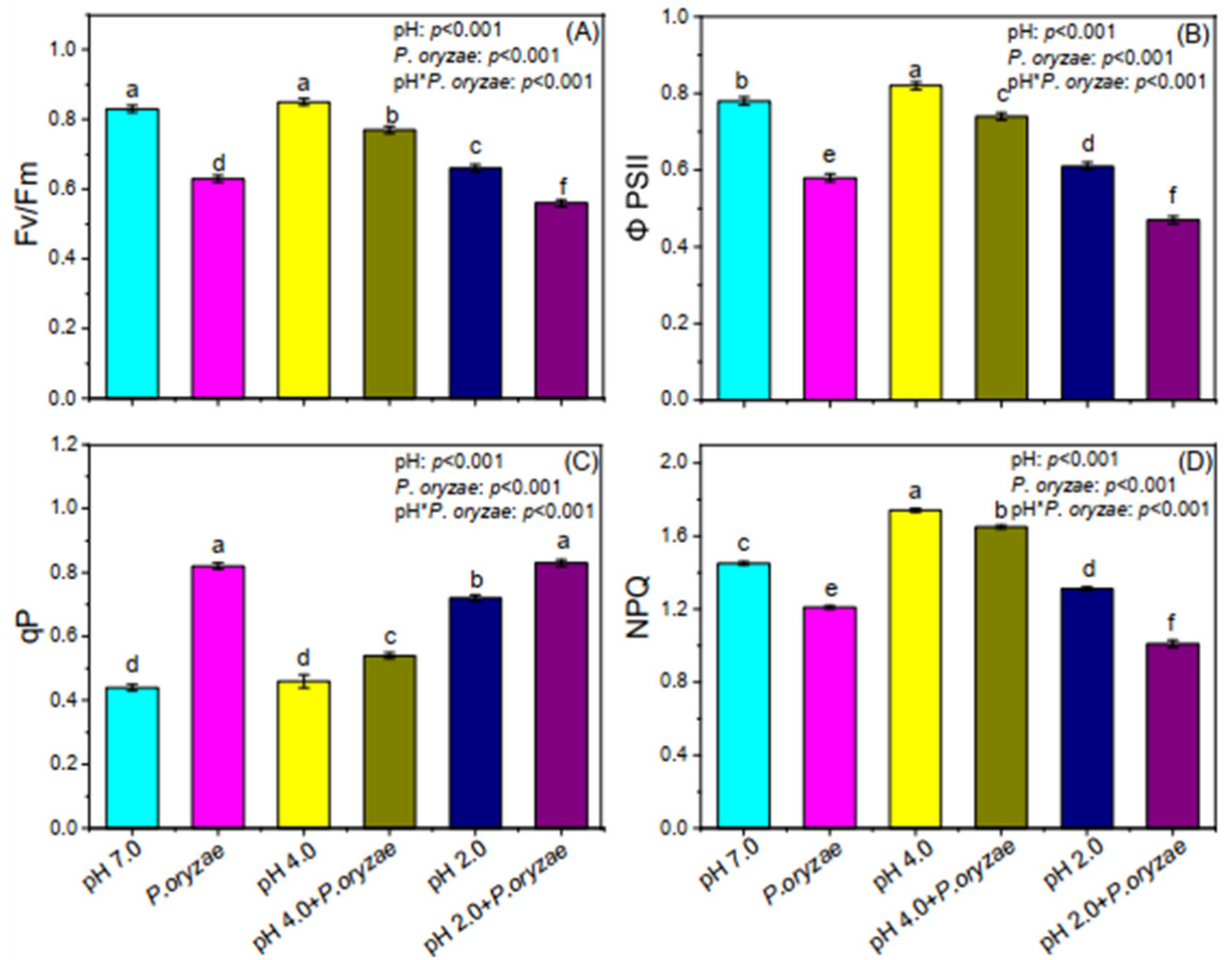

Figure 3. Effects of SAR and P. oryza on the maximum quantum yield ( $\mathrm{Fv} / \mathrm{Fm}, \mathrm{A})$, potential activity of PSII (ФPSII, B), photochemical quenching (qP, C), and non-photochemical quenching of fluorescence (NPQ, D) in rice seedlings. Significant differences at $p<0.05$ are shown with different lowercase letters. Values are the average \pm standard error $(n=9)$.

\subsection{Combined Effects of SAR and P. oryzae on Chloroplast Ultrastructure}

Under natural conditions, the chloroplast was complete, elliptical, and uniformly distributed on the plasma membrane; the granum and stroma thylakoids were arranged in an orderly manner; and the lamellar structure was tightly arranged (Figure 4A). Under $\mathrm{pH} 4.0$, the structure of the chloroplast did not observably change, but the stroma thylakoid was arranged more regularly, and the thylakoid lamellar structure was thicker than that of the control (Figure 4B). Under the single $\mathrm{pH} 2.0$ treatment, the chloroplast morphologically became deformed and atrophied, while the thylakoid became swelled and fuzzy, and the thylakoid lamellar structure loosed and revealed reduced grana stacking (Figure 4C). When inoculated with P. oryzae treatment (Figure 4D), the shape of the chloroplast was deformed, the plasma membrane was ruptured, the granum thylakoid was thinned, the lamellar structure of thylakoid was loose and disordered, and the cytoplasmic wall separated, compared with the control. Under the combination treatments of $\mathrm{pH} 4.0$ and P. oryza (Figure 4E), the chloroplast ultrastructure was unbroken, and the grana thylakoids were in an orderly arrangement, but the lamellar structure of thylakoid was loose. The chloroplast structure damage was especially serious under the combination treatments of $\mathrm{pH} 2.0$ and $P$. oryza, the chloroplast membrane structure ruptured and the matrix flowed out, and the thylakoid was disintegrated (Figure $4 \mathrm{~F}$ ). 

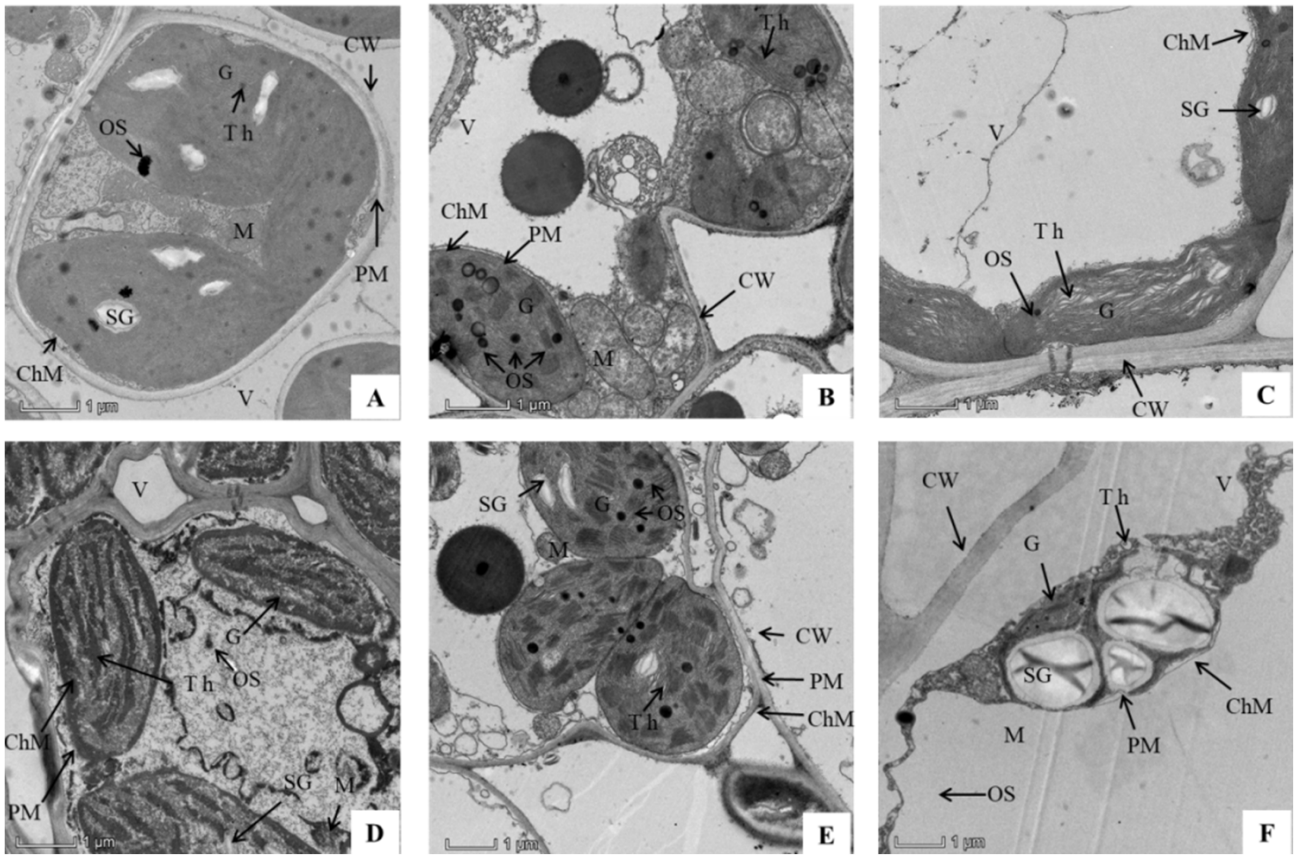

Figure 4. TEM images of the mesophyll cells in rice seedlings (A) treated without SAR and P. oryzae (control), (B) treated with acid rain at $\mathrm{pH} 4.0,(\mathbf{C})$ treated with acid rain at $\mathrm{pH} 2.0,(\mathrm{D})$ inoculated with P. oryzae, (E) treated with $\mathrm{pH} 4.0$ and P. oryzae, and (F) treated with $\mathrm{pH} 2.0$ and P. oryzae. ChM: chloroplast membrane; CW: cell wall; G: grana; M, mitochondrion; Th: thylakoid; OS: osmium; PM: plasma membrane; SG: starch granule; V: vacuole.

\subsection{Linking Rice Seedling Growth Indices with Photosynthetic Pigments, Photosynthetic Parameters, and Chlorophyll Fluorescence}

In the redundancy analysis (RDA) of seedling growth, we determined the interrelationship between acid rain and P. oryzae treatments and growth indices and photosynthetic properties of rice seedlings (Figure 5A). The height, biomass, leaf area, Chla, Chlb, Car, $\mathrm{Chla} / \mathrm{Chlb}, \mathrm{Fv} / \mathrm{Fm}$, $\Phi P S I I$, and NPQ were positively correlated with acid rain $\mathrm{pH}$, whereas negatively correlated with $P$. oryzae $(p<0.05)$. However, $\mathrm{qP}$ was negatively or positively correlated with acid rain $\mathrm{pH}$ and $P$. oryzae, respectively $(p<0.05)$.

We observed the relationships between the Tr and photosynthetic pigment contents under the combination treatment of $\mathrm{pH} 4.0$ and P. oryzae (Figure 5B), and treated with combination treatment of $\mathrm{pH} 2.0$ and P. oryzae (Figure 5C), respectively. We found that under the combination treatment of $\mathrm{pH} 4.0$ and P. oryzae, Tr correlated significantly with Chlb content in leaves $\left(R^{2}=0.558, p<0.024\right)$, and Chla/Chlb ratio $\left(R^{2}=0.683, p<0.006\right)$. These indexes revealed no significant correlation under the combination treatment of $\mathrm{pH} 2.0$ and P. oryzae. Tr was significantly and negatively correlated with Chla content under the combination treatment of $\mathrm{pH} 2.0$ and P. oryzae $\left(R^{2}=0.630, p<0.010\right)$, but no correlation under the combination treatment of $\mathrm{pH} 4.0$ and P. oryzae. 

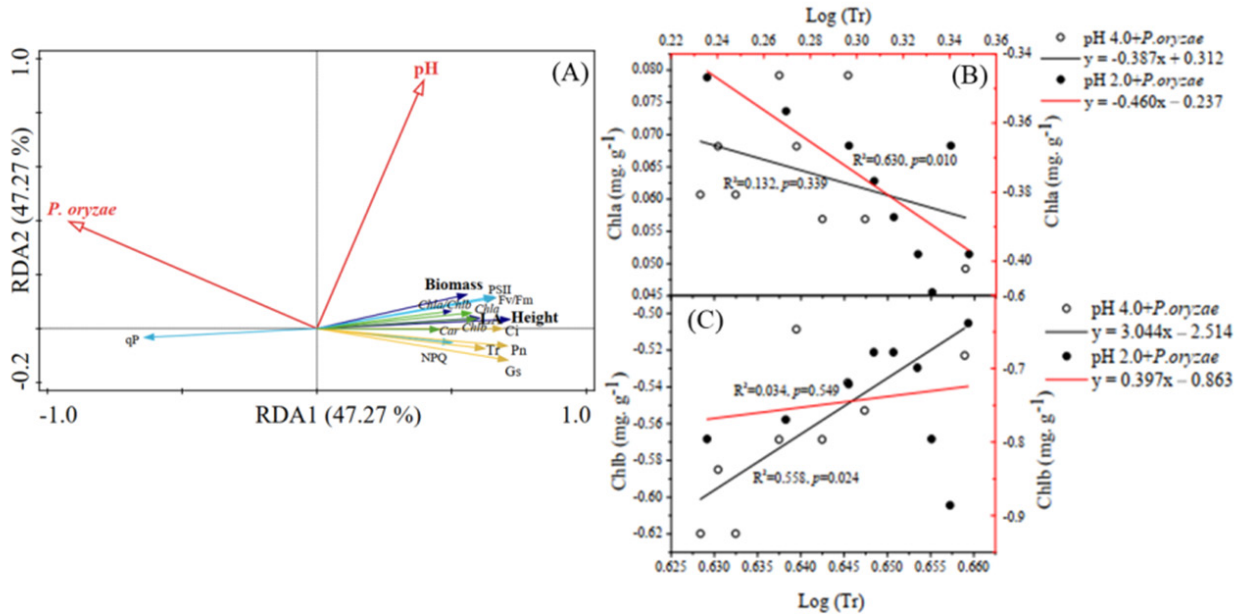

Figure 5. Redundancy analysis (RDA) of growth traits and photosynthetic properties under the combined effect of SAR and P. oryzae (A). Linear regression between Tr and Chla content under SAR and P. oryzae treatment (B). Linear regression between $\mathrm{Tr}$ and Chlb content under SAR and $P$. oryzae treatment $(\mathbf{C})$. The angle and length of the arrows indicate the direction and strength of the relationship of each index, respectively. In the picture, P. oryzae is the inoculation treatments of $P$. oryzae, $\mathrm{pH}$ is the $\mathrm{pH}$ of SAR, LA is leaf area, Chla is the content of chlorophyll a, Chlb is the content of chlorophyll b, Car is the content of carotenoid. Chla/Chlb is the ratio of Chla to Chlb, Pn is net photosynthetic rate, $\mathrm{Ci}$ is intercellular $\mathrm{CO}_{2}$ concentration, $\mathrm{Tr}$ is transpiration rate, $\mathrm{Gs}$ is stomatal conductance, Fv / Fm is the maximal efficiency of photosystem II (PSII) photochemistry, PSII is the effective efficiency of PSII photochemistry, qP is photochemical quenching coefficient, NPQ is non-photochemical quenching coefficient. The regression equation $\mathrm{R}^{2}$ and their significance level $(p<0.05)$ are shown.

\subsection{SEM Results}

The direct positive effects of acid rain $\mathrm{pH}$ on Gs $(0.173, p<0.01)$ and biomass $(0.064$, $p<0.01$ ) were significant (Figure 6). P. oryzae affected Gs, Chla/Chlb and NPQ through a indirect negative path and biomass through a direct negative path. The direct effect of acid rain $\mathrm{pH}(0.064, p<0.01)$ on biomass was significantly lower than that of $P$. oryzae $(0.234$, $p<0.01)$. Pn and Chla/Chlb ratios had a direct effect on the biomass of rice seedlings. These drivers showed different effect coefficients and directions between acid rain and $P$. oryzae. Thus, the total effects of acid rain $\mathrm{pH}$ and P. oryzae on biomass were 0.22 and 0.92 , respectively.

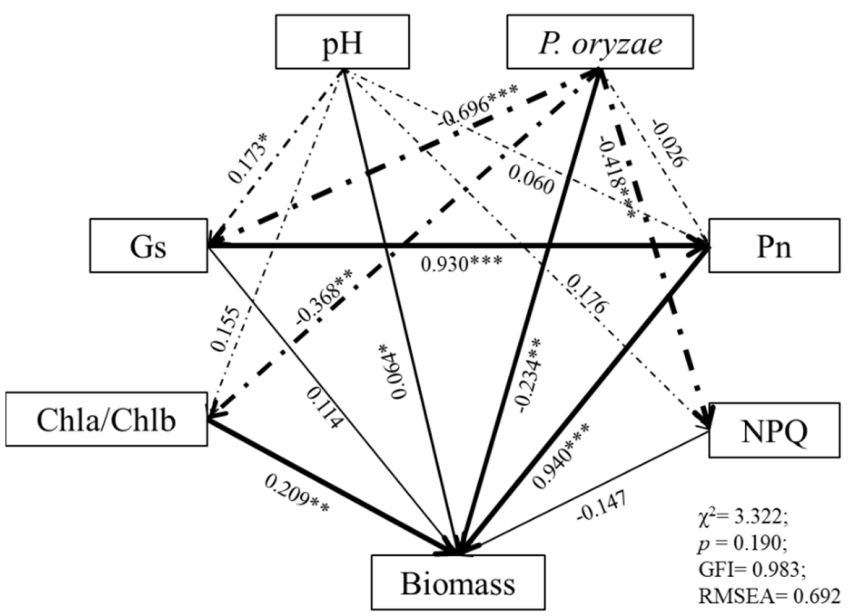

Figure 6. Structural equation models of SAR $(\mathrm{pH})$ and inoculation of $P$. oryzae effects on rice biomass. Significant values are indicated by ${ }^{*}(p<0.1),{ }^{* *}(p<0.05)$ or ${ }^{* * *}(p<0.001)$. The numbers 
on the arrows are normalized path coefficients. The width of the arrows indicates the strength of the causal influence. Solid arrows indicate a direct effect on biomass; dashes represent pathways that affect biomass indirectly. $\mathrm{pH}$ : the $\mathrm{pH}$ of the SAR; P. oryzae: inoculation of P. oryzae; Chla/Chlb: the ratio of Chla to Chlb; Pn: net photosynthetic rate; Gs: stomatal conductance; NPQ: non-photochemical quenching coefficient.

\section{Discussion}

\subsection{Negative Effect of P. oryzae on the Photosynthesis in Rice Leaves}

Photosynthesis in crops is often found to be impaired by foliar diseases $[7,29,30]$. Stomata located in the epidermis of plants are the main structure for gas exchange in photosynthesis, respiration, and transpiration [31]. However, P. oryzae can use the stomata as a channel to invade plants [32]. In this study, infection by P. oryzae on rice leaves caused serious effects on photosynthetic gas exchange, photosynthetic pigment content, and chlorophyll fluorescence parameters (Figures 1-3). Based on the observed effects of $P$. oryzae on plant photosynthesis, three interconnected interpretations explain the reduction in plant photosynthesis and biomass. First, P. oryzae infection disrupted the ultrastructure of chloroplast, separated the cytoplasmic wall, thinned the granum thylakoid, and disordered the lamellar structure of thylakoid (Figure 4D). Second, P. oryzae infection reduced stomatal conductance (Figure 1D). Stomatal conductance is a main factor affecting photosynthesis, which determines the reduction of $\mathrm{CO}_{2}$ influx [32]. Third, infection with P. oryzae reduced the contents of photosynthetic pigments (Figure 2), which is mainly due to changes in composition of the thylakoid membrane caused by pathogen infection, leading to accelerated chlorophyll degradation or reduced chlorophyll synthesis [33].

\subsection{Antagonistic Effect of Medium Acidity SAR on P. oryzae-Induced Influence}

In the present study, we found that the medium-acidity rain played a decisive role in plant tolerance to $P$. oryzae by protecting the ultrastructural of chloroplasts from damage (Figure 4), thereby improving photosynthesis and the growth indices of rice (Table 1 and Figure 4). The RDA analysis showed that the growth indices and photosynthetic parameters of rice seedlings were positively correlated (Figure 5A). Medium-acidity rain often acts as a nitrogenous fertilizer to improve seedling growth rate and biomass accumulation (Table 1 and Figure 4) [18,34]. Photosynthesis is a basic physiological process of plant biomass, and changes to the Pn can directly reflect the response of plant photosynthetic physiology to stress [35]. Some evidence indicates that major factors to affect Pn, including the regulation of stomata opening and the photosynthetic activity of mesophyll cells [36,37]. We found that SAR pH 4.0 promoted Gs, enhanced the transport of $\mathrm{CO}_{2}$ to chloroplasts, provided sufficient substances for photosynthesis, increased Pn, and finally increased rice biomass. In addition, SAR pH 4.0 also increased Pn by promoting the efficiency of electron transport (Fv/Fm) and light utilization (PSII) (Figure 3), inducing the formation of the photosynthetic pigment (carotenoid, Figure 2C), and improving the chloroplast ultrastructure (Figure 4B). A similar result was also obtained in previous research [14,38]. These effects show that mediumacidity rain could improve the status of plant light and dark reaction systems and promote plant growth. Moreover, we suppose that increased chlorophyll and carotenoid contents in leaves treated with medium-acidity rain and $P$. oryzae may contribute to moderate the damage of leaf photosynthesis by P. oryzae (Figures 2 and 3), because carotenoids act as antioxidants and protect the photosynthetic apparatus from damage caused by environmental stress $[39,40]$. These functions improve the light absorption and utilization abilities of chloroplast functional elements, enhancing the photosynthetic pigment synthesis and the photosynthesis light and dark reaction process [14].

\subsection{Synergistic Effect of High Acidity SAR and P. oryzae-Induced Influence}

Previous studies had revealed that, when the $\mathrm{pH}$ value of acid rain falls below the optimal threshold of plants, the negative effects of excess $\mathrm{H}^{+}$become stronger than the "fertilization effect" [41], and can lead to serious acidification and the loss of intracellular 
water [42], disrupting the homeostasis of plant cells, and hindering growth and development in plants $[43,44]$. A decrease in growth indices (Table 1 ) suggested that strongly acidic rain ( $\mathrm{pH}$ 2.0) had exceeded the optimal threshold for rice and significantly inhibited plant growth [14]. This verified the decline of the photosynthetic parameters and the PSII activity and the damage of the chloroplast (Figure 4C). The great decline of photosynthetic parameters and photosynthetic pigments at $\mathrm{pH} 2.0$ treatments suggest that the highly acidic rain not only limited the stomatal opening and $\mathrm{CO}_{2}$ diffusing into the cell, but also caused the degradation of photosynthetic pigments (Figures 1 and 2), which was consistent with previous studies $[18,45,46]$.

When rice seedlings were synchronously treated with high-acidity rain and P. oryzae, we observed synergistic effects on photosynthesis and the inhibition on the growth index of the rice seedlings increased (Table 1; Figure 1). The high-acidity rain and P. oryzae also aggravated adverse changes of the chlorophyll fluorescence which can be partly attributed to the loss of photosynthetic pigments (Figure 2). High-acidity rain reduces photosynthesis by inhibiting the synthesis of photosynthetic pigments (Chla, Chlb, Car, and Chla/Chlb) and decreasing the $\mathrm{Fv} / \mathrm{Fm}$ ratio [47]. Moreover, the high acid rain promoted P. oryzae to destroy the chloroplast ultrastructure in rice cells more than the moderate acid rain (Figure 4E,F). The synergistic effect of high-acidity rain and P. oryzae damaged the plant. The ROS accumulation due to less photosynthetic pigments destroys the structure of the chloroplast and electron transfer, reduces the photosynthesis and fluorescence intensity $[48,49]$, and weakens the resistance of plants to pathogens [24].

\subsection{Correlations between Tr and Content of Chla and Chlb of Rice Seedlings}

Interestingly, in our study, we found that the correlation between the Tr and Chlb content under the combined $\mathrm{pH} 4.0$ and P. oryzae treatment was stronger than that of $\mathrm{pH} 2.0$ and P. oryzae treatment (Figure 5C), but the correlation between Tr and Chla content under the combined $\mathrm{pH} 2.0$ and P. oryzae treatment was significantly stronger than that under the combined $\mathrm{pH} 4.0$ and P. oryzae treatment (Figure 5B). This may be because the combined stress of acid rain and pathogens on the one hand induces plant stomata to open or close [50], which changes the water loss through stomata transpiration, and on the other hand stimulates the content of Chla and Chlb in leaves. Thus, the correlation between $\mathrm{Tr}$ and chlorophyll content indicates that $\mathrm{Tr}$ and chlorophyll contents were synergistic in response to the combined stress of acid rain and P. oryzae. The present study found that Chla can tolerate more acidic acid rain than Chlb, which suggests that the synergistic mechanism of plant traits changes under different acid rain treatments. The changes in the correlation between $\mathrm{Tr}$ and chlorophyll content under different acidity treatments may be due to the different sensitivity of different pigments to acid rain acidity [51]. These results indicate that the pigment content and $\mathrm{Tr}$ can alleviate the damage caused by environmental stress on plant photosynthetic properties through synergistic response.

\section{Conclusions}

Plant growth, photosynthetic capacity, and chloroplast structural integrity were suppressed as acid rain $\mathrm{pH}$ decreased in acid rain treatments. P. oryzae destroyed the photosynthetic system in the same way as the high-acidity rain, but more severely, resulting in reduced light absorption and photosynthesis, and ultimately inhibiting the growth and development of rice. Thus, high-acidity rain and P. oryzae aggravated the damage to the chloroplast structure, cumulatively injuring the physiological processes of the rice leaves. Medium-acidity rain protected the photosynthetic system from the dysfunction caused by $P$. oryzae by stimulating the photosynthesis and chlorophyll contents and repairing the chloroplast structure. In other words, the reduction in growth and photosynthetic characteristics and the destruction of the chloroplast ultrastructure of rice seedlings by $P$. oryzae depend on the threshold of acid rain. Moreover, this study found that the correlation between chlorophyll content and photosynthesis under medium-acidity rain stress was 
stronger than that in high-acidity rain stress, indicating the significance of the synergistic regulation of traits in rice stress tolerance (Figure 7).

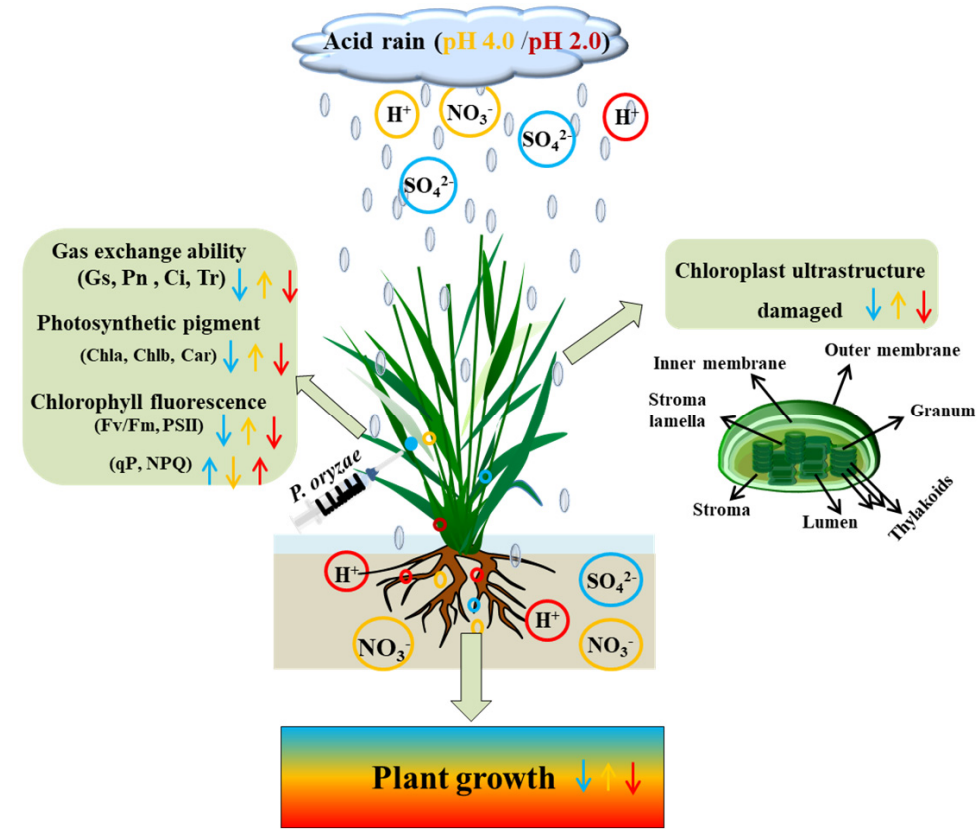

Figure 7. The mechanisms of SAR $(\mathrm{pH})$ and inoculation of P. oryzae effects on plant growth. The blue, yellow, and red arrows indicate the changes induced by inoculation with $P$. oryzae, mediumacidity acid rain ( $\mathrm{pH} 4.0)$ and high-acidity acid rain ( $\mathrm{pH} 2.0)$, respectively; up and down arrows indicate up- and down-regulation of traits, respectively. Gs, stomatal conductance; Pn, net photosynthetic rate; $\mathrm{Ci}$, intercellular $\mathrm{CO}_{2}$ concentration; $\mathrm{Tr}$, transpiration rate; Chla, Chlorophyll a; Chlb, Chlorophyll b; Car, Cartenoid; Fv/Fm, maximum quantum yield; PSII, potential activity of PSII; qP, photochemical quenching; and NPQ, non-photochemical quenching of fluorescence. As the figure shows, medium-acidity acid rain can help the plant to cope with the detrimental effect of $P$. oryzae on plant photosynthetic characteristics and chloroplast structure, while the scenario is just reversed in case of high-acidity acid rain and P. oryzae.

Author Contributions: Conceptualization, H.L. and J.Z.; methodology, H.L.; software, H.L., Q.X. and H.W.; validation, H.L. and Q.X.; formal analysis, H.L.; investigation, Q.W., C.L. and Y.L.; resources, Q.W., Y.L., C.L. and Z.Q.; data curation, H.L.; writing-original draft preparation, H.L.; writingreview and editing, H.W., Q.X. and J.Z.; visualization, H.L.; supervision, J.Z., Q.X. and H.X.; project administration, J.Z.; funding acquisition, J.Z. All authors have read and agreed to the published version of the manuscript.

Funding: This research was funded by the National Natural Science Foundation of China (U1701236), Science and Technology Planning Project of Guangdong Province, China (2019B030301007), and Guangdong Laboratory for Lingnan Modern Agriculture Project (grant number NT2021010).

Institutional Review Board Statement: Not applicable.

Informed Consent Statement: Not applicable.

Data Availability Statement: All data generated or analyzed during this study are included in this published article.

Acknowledgments: We thank the students in our lab for their experiment support.

Conflicts of Interest: The authors declare no conflict of interest. 


\section{References}

1. Mentlak, T.A.; Kombrink, A.; Shinya, T.; Ryder, L.S.; Otomo, I.; Saitoh, H.; Terauchi, R.; Nishizawa, Y.; Shibuya, N.; Thomma, B.P.H.J.; et al. Effector-mediated suppression of chitin-triggered immunity by Magnaporthe oryzae is necessary for rice blast disease. Plant Cell 2012, 1, 322-335. [CrossRef] [PubMed]

2. Marroquin-Guzman, M.; Hartline, D.; Wright, J.D.; Elowsky, C.; Bourret, T.J.; Wilson, R.A. The Magnaporthe oryzae nitrooxidative stress response suppresses rice innate immunity during blast disease. Nat. Microbiol. 2017, 2, 17054. [CrossRef] [PubMed]

3. Domiciano, G.P.; Cacique, I.S.; Chagas, F.C.; Filippi, M.C.; DaMatta, F.M.; Do, V.F.; Rodrigues, F.A. Alterations in gas exchange and oxidative metabolism in rice leaves infected by Pyricularia oryzae are attenuated by silicon. Phytopathology 2015, 6, 738-747. [CrossRef] [PubMed]

4. $\quad$ Li, X.; He, Y.; Xie, C.; Zu, Y.; Zhan, F.; Mei, X.; Xia, Y.; Li, Y. Effects of UV-B radiation on the infectivity of Magnaporthe oryzae and rice disease-resistant physiology in yuanyang terraces. Photochem. Photobiol. Sci. 2018, 1, 8-17. [CrossRef] [PubMed]

5. Gao, D.; Cai, K.; Chen, J.; Luo, S.; Zeng, R.; Yang, J.; Zhu, X. Silicon enhances photochemical efficiency and adjusts mineral nutrient absorption in Magnaporthe oryzae infected rice plants. Acta Physiol. Plant. 2010, 33, 675-682. [CrossRef]

6. Alves, A.A.; Guimarães, L.M.D.S.; Chaves, A.R.D.M.; DaMatta, F.M.; Alfenas, A.C. Leaf gas exchange and chlorophyll a fluorescence of Eucalyptus urophylla in response to Puccinia psidii infection. Acta Physiol. Plant. 2011, 33, 1831-1839. [CrossRef]

7. Resende, R.S.; Rodrigues, F.Á.; Cavatte, P.C.; Martins, S.; Moreira, W.R.; Chaves, A.; Damatta, F.M. Leaf gas exchange and oxidative stress in sorghum plants supplied with silicon and infected by Colletotrichum sublineolum. Phytopathology 2012, 9 , 892-898. [CrossRef]

8. Fisher, M.C.; Henk, D.A.; Briggs, C.J.; Brownstein, J.S.; Madoff, L.C.; Mccraw, S.L.; Gurr, S.J. Emerging fungal threats to animal, plant and ecosystem health. Nature 2012, 7393, 186-194. [CrossRef]

9. Wei, H.; Liu, W.; Zhang, J.; Qin, Z. Effects of simulated acid rain on soil fauna community composition and their ecological niches. Environ. Pollut. 2017, 220, 460-468. [CrossRef]

10. Liu, X.; Zhang, B.; Zhao, W.; Wang, L.; Xie, D.; Huo, W.; Wu, Y.; Zhang, J. Comparative effects of sulfuric and nitric acid rain on litter decomposition and soil microbial community in subtropical plantation of Yangtze River Delta region. Ence Total Environ. 2017, 601-602, 669-678. [CrossRef]

11. Imran, M.A.; Hussain, S.; Hussain, M.; Meo, A.A. Effect of simulated acid rain (SAR) on some morphochemical aspects of mash (Vigna mungo L.). Pak. J. Bot. 2014, 46, 245-250.

12. Ramlall, C.; Varghese, B.; Ramdhani, S.; Pammenter, N.W.; Bhatt, A.; Berjak, P. Effects of simulated acid rain on germination, seedling growth and oxidative metabolism of recalcitrant-seeded Trichilia dregeana grown in its natural seed bank. Physiol. Plant. 2015, 153, 149-160. [CrossRef] [PubMed]

13. Macaulay, B.M.; Enahoro, G.E. Effects of simulated acid rain on the morphology, phenology and dry biomass of a local variety of maize (Suwan-1) in Southwestern Nigeria. Environ. Monit. Assess. 2015, 10, 621-622. [CrossRef] [PubMed]

14. Wen, K.; Liang, C.; Wang, L.; Hu, G.; Zhou, Q. Combined effects of lanthanumion and acid rain on growth, photosynthesis and chloroplast ultrastructure in soybean seedlings. Chemosphere 2011, 84, 601-608. [CrossRef] [PubMed]

15. Sun, Z.G.; Wang, L.H.; Chen, M.M.; Wang, L.; Liang, C.J.; Zhou, Q.; Huang, X.H. Interactive effects of cadmium and acid rain on photosynthetic light reaction in soybean seedlings. Ecotoxicol. Environ. Saf. 2012, 79, 62-68. [CrossRef] [PubMed]

16. Wang, L.; Wang, W.; Zhou, Q.; Huang, X. Combined effects of lanthanum (III) chloride and acid rain on photosynthetic parameters in rice. Chemosphere 2014, 112, 355-361. [CrossRef]

17. Polishchuk, O.V.; Vodka, M.V.; Belyavskaya, N.A.; Khomochkin, A.P.; Zolotareva, E.K. The effect of acid rain on ultrastructure and functional parameters of photosynthetic apparatus in pea leaves. Cell Tissue Biol. 2016, 10, 250-257. [CrossRef]

18. Liu, M.; Korpelainen, H.; Dong, L.; Yi, L. Physiological responses of Elaeocarpus glabripetalus seedlings exposed to simulated acid rain and cadmium. Ecotoxicol. Environ. Saf. 2019, 15, 118-127. [CrossRef]

19. Liu, M.H.; Yi, L.T.; Yu, S.Q.; Yu, F.; Yin, X.M. Chlorophyll fluorescence characteristics and the growth response of Elaeocarpus glabripetalus to simulated acid rain. Photosynthetica 2015, 1, 23-28. [CrossRef]

20. Zhang, C.; Yi, X.; Gao, X.; Wang, M.; Shao, C.; Lv, Z.; Chen, J.; Liu, Z.; Shen, C. Physiological and biochemical responses of tea seedlings (Camellia sinensis) to simulated acid rain conditions. Ecotoxicol. Environ. Saf. 2020, 192, 110315. [CrossRef]

21. Shu, X.; Zhang, K.; Zhang, Q.; Wang, W. Ecophysiological responses of Jatropha curcas L. seedlings to simulated acid rain under different soil types. Ecotoxicol. Environ. Saf. 2019, 185, 109705. [CrossRef] [PubMed]

22. Ren, X.; Zhu, J.; Liu, H.; Xu, X.; Liang, C. Response of antioxidative system in rice (Oryza sativa) leaves to simulated acid rain stress. Ecotoxicol. Environ. Saf. 2018, 148, 851-856. [CrossRef]

23. Li, Y.; Liang, C. Exogenous application of $\mathrm{Ca}^{2+}$ mitigates simulated acid rain stress on soybean productivity and quality by maintaining nutrient absorption. Environ. Sci. Pollut. Res. 2019, 26, 4975-4986. [CrossRef] [PubMed]

24. Li, H.; Xiang, H.; Zhong, J.; Ren, X.; Wei, H.; Zhang, J.; Xu, Q.; Zhao, B. Acid rainincreases impact of rice blast on crop health via inhibition of resistance enzymes. Plants 2020, 7, 881. [CrossRef] [PubMed]

25. Huang, D.Y.; Xu, Y.G.; Peng, P.; Zhang, H.H.; Lan, J.B. Chemical composition and seasonal variation of acid deposition in Guangzhou, South China: Comparison with precipitation in other major Chinese cities. Environ. Pollut. 2009, 157, 35-41. [CrossRef] [PubMed]

26. Lichtenthaler, H.; Lichtenthaler, H.K.; Lichtenthaler, H.K.; Lichtenthaler, H.K.; Lichtenthaler, H.K. Chlorophylls and carotenoids: Pigment photosynthetic biomembranes. Methods Enzymol. 1987, 1, 350-382. 
27. Wang, T.; Yang, W.; Xie, Y.; Shi, D.; Ma, Y.; Sun, X. Effects of exogenous nitric oxide on the photosynthetic characteristics of bamboo (Indocalamus barbatus McClure) seedlings under acid rain stress. Plant Growth Regul. 2017, 82, 69-78. [CrossRef]

28. Helliot, B.; Swennen, R.; Poumay, Y.; Frison, E.; Lepoivre, P.; Panis, B. Ultrastructural changes associated with cryopreservation of banana (Musa spp.) highly proliferating meristems. Plant Cell Rep. 2003, 21, 690. [CrossRef]

29. Scholes, J.D.; Rolfe, S.A. Photosynthesis in localised regions of oat leaves infected with crown rust (Puccinia coronata): Quantitative imaging of chlorophyll fluorescence. Planta 1996, 199, 573-582. [CrossRef]

30. Dallagnol, L.J.; Rodrigues, F.A.; DaMatta, F.M.; Mielli, M.; Pereira, S.C. Deficiency in silicon uptake affects cytological, physiological, and biochemical events in the rice-Bipolaris oryzae interaction. Phytopathology 2011, 101, 92-104. [CrossRef]

31. Haruki, K.; Mimi, H.S.; Koh, I.; Ichiro, T.; Wataru, Y. Improved stomatal opening enhances photosynthetic rate and biomass production in fluctuating light. J. Exp. Bot. 2020, 71, 2339-2350.

32. Rios, J.A.; Rodrigues, F.D.; Debona, D.; Silva, L.C. Photosynthetic gas exchange in leaves of wheat plants supplied with silicon and infected with Pyricularia oryzae. Acta Physiol. Plant. 2014, 36, 371-379. [CrossRef]

33. Smirnoff, N. Antioxidant systems and plant responses to the environment. In Environment and Plant Metabolism: Flexibility and Acclimation; Sminorff, N., Ed.; Bios Scientific Publishers: Oxford, UK, 1995; pp. 217-243.

34. Mofunanya, A.; Soonen, L. Physiological and morphological responses of Amaranthus hybridus L. (green) to simulated nitric and sulphuric acid rain. Br. J. Appl. Sci. Technol. 2017, 21, 1-12. [CrossRef]

35. Sun, J.; Gu, J.; Zeng, J.; Han, S.; Song, A.; Chen, F.; Fang, W.; Jiang, J.; Chen, S. Changes in leaf morphology, antioxidant activity and photosynthesis capacity in two different drought-tolerant cultivars of chrysanthemum during and after water stress. Entia Hortic. 2013, 161, 249-258. [CrossRef]

36. Velikova, V.; Tsonev, T.; Yordanov, I. Light and $\mathrm{CO}_{2}$ responses of photosynthesis and chlorophyll fluorescence characteristics in bean plants after simulated acid rain. Physiol. Plant. 1999, 107, 77-83. [CrossRef]

37. Sharma, A.; Kumar, V.; Shahzad, B.; Ramakrishnan, M.; Singh Sidhu, G.P.; Bali, A.S.; Handa, N.; Kapoor, D.; Yadav, P.; Khanna, K.; et al. Photosynthetic response of plants under different abiotic stresses: A review. J. Plant Growth Regul. 2020, 39, 509-531. [CrossRef]

38. Su, Y.Y.; Qin, C.; Begum, N.; Ashraf, M.; Zhang, L.X. Acetylcholine ameliorates the adverse effects of cadmium stress through mediating growth, photosynthetic activity and subcellular distribution of cadmium in tobacco (Nicotiana benthamiana). Ecotoxicol. Environ. Saf. 2020, 198, 110671. [CrossRef]

39. Gao, P.; Zuo, Z.; Wu, X.; Gao, Y.; Gao, R.; Zhang, R. Effects of cycloheximide on photosynthetic abilities, reflectance spectra and fluorescence emission spectra in Phyllostachys edulis. Trees 2016, 30, 719-732. [CrossRef]

40. Ahmad, P.; Jaleel, C.A.; Salem, M.A.; Nabi, G.; Sharma, S. Roles of enzymatic and nonenzymatic antioxidants in plants during abiotic stress. Crit. Rev. Biotechnol. 2010, 30, 161-175. [CrossRef]

41. Liu, Z.; Li, D.; Zhang, J.; Saleem, M.; Zhang, Y.; Ma, R.; He, Y.; Yang, J.; Xiang, H.; Wei, H. Effect of simulated acid rain on soil $\mathrm{CO}_{2}, \mathrm{CH}_{4}$ and $\mathrm{N}_{2} \mathrm{O}$ emissions and microbial communities in an agricultural soil. Geoderma 2020, 366, 114222. [CrossRef]

42. Sun, J.; Hu, H.; Li, Y.; Wang, L.; Zhou, Q.; Huang, X. Effects and mechanism of acid rain on plant chloroplast ATP synthase. Environ. Sci. Pollut. Res. 2016, 23, 18296-18306. [CrossRef] [PubMed]

43. Liang, C.; Zhang, B. Effect of exogenous calcium on growth, nutrients uptake and plasma membrane $\mathrm{H}^{+}-\mathrm{ATPase}$ and $\mathrm{Ca}^{2+}-$ ATPase activities in soybean (Glycine max) seedlings under simulated acid rain stress. Ecotoxicol. Environ. Saf. 2018, 165, 261-269. [CrossRef] [PubMed]

44. Liu, X.; Fu, Z.; Zhang, B.; Zhai, L.; Meng, M.; Lin, J.; Zhuang, J.; Wang, G.G.; Zhang, J. Effects of sulfuric, nitric, and mixed acid rain on Chinese fir sapling growth in Southern China. Ecotoxicol. Environ. Saf. 2018, 160, 154-161. [CrossRef] [PubMed]

45. Hu, H.; Wang, L.; Zhou, Q.; Huang, X. Combined effects of simulated acid rain and lanthanum chloride on chloroplast structure and functional elements in rice. Environ. Sci. Pollut. Res. 2016, 23, 8902-8916. [CrossRef]

46. Pinto, S.; Souza, A.E.; Oliva, M.A.; Pereira, E.G. Oxidative damage and photosynthetic impairment in tropical rice cultivars upon exposure to excess iron. Sci. Agric. 2016, 73, 217-226. [CrossRef]

47. Zhang, C.; Zhao, W.; Sasaki, S.; Tamiaki, H.; Wang, X. A chlorophyll derivative-based bio-solar energy conversion and storage device. Electrochim. Acta 2020, 347, 136283. [CrossRef]

48. Sena, L.A.; Navdeep, S. Chandel, Physiological roles of mitochondrial reactive oxygen specie. Mol. Cell 2012, $48,158-167$. [CrossRef]

49. Richman, D.E.; Majumdar, A.; García-Moreno, E.B. pH dependence of conformational fluctuations of the protein backbone. Proteins: Struct. Funct. Bioinform. 2014, 82, 3132-3143. [CrossRef]

50. Murray, R.R.; Emblow, M.S.M.; Hetherington, A.M.; Foster, G.D. Plant virus infections control stomatal development. Sci. Rep. 2016, 6, 34507. [CrossRef]

51. Du, E.Z.; Dong, D.; Zeng, X.T.; Sun, Z.Z.; Jiang, X.F.; Vries, W.D. Direct effect of acid rain on leaf chlorophyll content of terrestrial plants in China. Sci. Total Environ. 2017, 605, 764-769. [CrossRef] 